\title{
UN PRÓLOGO COSMOPOLITA Sobre algunas tradiciones en el Prólogo de Juan
}

\section{Resumen}

Los textos bíblicos de Gn 1 y 2 reflejan un antiguo debate entre la religión de Israel y la de Egipto, usando lenguaje y categorías similares a los egipcios. Quizá por ello las comunidades judeo-helénicas de Egipto, más aptas para comprender, conservar y transmitir esa dialéctica y su incidencia en las tradiciones, desarrollaron un tipo de literatura en consonancia con las mismas. La obra filónica es una ejemplo de este ejercicio, y la literatura de Nag Hammadi hace lo propio. La comunidad joánica estuvo probablemente familiarizada con este tipo de hermenéutica de Gn 1 y 2, y elabora una cristología propia superadora con un lenguaje acorde al mundo cosmopolita que le tocó compartir y capaz de enfrentar la presión del culto imperial, impregnado de la cosmovisión egipcia.

Palabras clave: Prólogo. Evangelio de Juan. Nag Hammadi. Filón. Culto imperial.

\section{El debate sobre las tradiciones en el evangelio de Juan}

Las diferencias entre el evangelio de Juan y los evangelios sinópticos siempre han sido motivo de estudio. Para poder explicar su "originalidad" se han propuesto distintas vertientes. Algunos autores hablan de elementos comunes con las tradiciones sinópticas reelaborados en sucesivas ediciones del texto (Barret, Boismard, Brown, Dodd, Lindars, etc.). Otros plantean una fuente de signos con las que el autor del cuarto evangelio habría desarrollado elementos propios (Becker, Bultmann, Painter, Schnackenburg, etc.). Hay quienes proponen influencias gnósticas (Bultmann) o un posible trasfondo común con las tradiciones samaritanas (Keener, Murray). Otros apelan a tradiciones veterotestamentarias como las reflejadas 
en la literatura rabínica (Barrett), en las tradiciones sapienciales (Kysar, Brown) o en la literatura de Qumrán (Hunter). Esta lista de opiniones divergentes no pretende ser exhaustiva, sino ilustrativa ${ }^{1}$.

También es motivo de debate el contexto geográfico donde pudo haber surgido el evangelio de Juan. Aunque se acepta mayoritariamente que procede de la ciudad de Éfeso, en Asia Menor, son varios los autores que lo han relacionado con el judaísmo helénico de cuño alejandrino y sus interpretaciones del Antiguo Testamento ${ }^{2}$. Entre las razones figuran las afinidades entre el Logos joánico y el de Filón de Alejandría y el uso de imaginería común con la literatura hermética que proliferó en Egipto en los siglos II y III d. C. Por ejemplo, Dodd llegó a proponer el judaísmo rabínico, Filón de Alejandría y la literatura hermética como las fuentes más directas del pensamiento joánico ${ }^{3}$. Brown, en cambio, propone un trasfondo común entre la literatura filónica y la joánica, abrevando ambas en las tradiciones sobre la personificación de la Sabiduría, pero usando metodologías distintas ${ }^{4}$.

Todo este mosaico de vertientes puede hacernos perder de vista el ambiente común que compartieron las comunidades de Éfeso y Alejandría, que, junto a otras comunidades de la diáspora, habitaban la cuenca del Mediterráneo. En efecto, toda la zona costera marítima tuvo durante siglos un activo intercambio político, comercial, religioso y cultural que influyó sobre la religión de Israel. Y lo cierto es que las comunidades judías diseminadas por las costas del Mediterráneo estuvieron durante siglos en permanente contacto con las creencias religiosas de las naciones que las albergaron, produciendo literatura propia con fines apologéticos y también proselitistas ${ }^{5}$.

1 J. Beutler, "Méthodes et problèmes de la recherche johannique aujourd'hui", La communauté johannique et son histoire, Genève 1990, 15-38; V. MAGEZI - P. MANZAN$\mathrm{GA}$, "A study to establish the most plausible background to the Fourth Gospel (John)", HTS Teologiese Studies / Theological Studies 66 (2010).

2 C. K. Barret, The Gospel According to John, Westminster 1978, 129; E. GoodeNOUgH, “John a Primitive Gospel”, JBL 64 (1945) 145-182; E. Gould, “The Alexandrian Gospel”, JBL 19 (1900) 5-11; A. PerRY, “Is John an Alexandrian Gospel?”, JBL 63 (1944) 99-106; H. SNAPE, “The Fourth Gospel, Ephesus, and Alexandria”, HTR 47 (1954) 1-14.

${ }^{3}$ C. H. Dodd, Historical Tradition in the Fourth Gospel, Cambridge 1963, 33.

${ }^{4}$ R. E. Brown, The Gospel According to John I-II, New York 1966, LVII-LVIII. De modo similar piensa P. MANZANGA, A study of the Background of the Concepts "Life" and "Light" in the prologue of the Fourth Gospel. Tesis de Magister en Nuevo Testamento presentada en North West University (Potchefstroom Campus) 2007.

${ }^{5}$ G. Gestoso Singer, El intercambio de bienes entre Egipto y Asia Anterior desde el reinado de Tuthmosis III hasta el de Akhenaton, Society of Biblical Literature - Centro de Estudios de Historia del Antiguo Oriente (UCA) 2008; J. M. Tebes, Centro y periferia 
Llegado el período greco-romano, el judaísmo helénico ya tenía un largo trayecto de argumentación y defensa de sus propias tradiciones frente a los desafíos de un mundo cada vez más plural y cosmopolita. Hay pasajes del Nuevo Testamento que dan testimonio de este intercambio mencionando, por ejemplo que un tal Apolo proveniente de Alejandría fue a Éfeso (Hch 18,24); o remiten a una flota proveniente de Alejandría que transportaba a Pablo (Hch 27,6; 28,11).

En este contexto judeo-helénico tuvieron un papel privilegiado las comunidades judías egipcias que habitaban en el delta del Nilo, Tebas, Oxyrrinco y Fayum, entre las que sobresalía Alejandría ${ }^{6}$. Prueba de ello es que durante el período griego la comunidad judía de Alejandría era la más numerosa y poderosa de las comunidades judías en territorio egipcio, siendo incluso más próspera que la de Jerusalén. En el siglo I d. C., dicha ciudad tributó al Imperio romano doce veces más impuestos que todo el territorio de Judá ${ }^{7}$. Sus sinagogas prosperaron hasta el siglo II a. C. y contaron con el apoyo político y económico de los faraones. Hay dedicatorias que prueban el patronazgo ptolemaico sobre el culto judío durante el período griego ${ }^{8}$. De este modo se generó un cúmulo de literatura judía entre las que se encuentra la versión griega de la LXX, la literatura filónica y la literatura mística de cuño egipcio. La versión griega del Antiguo Testamento jugó un papel decisivo en el culto judío de la diáspora, proveyendo a las sinagogas de lecturas bíblicas capaces de ser entendidas por una audiencia que solo conociese el griego. A su vez, la literatura filónica nos ha permitido conocer un tipo de judaísmo particular en diálogo con la filosofía de la época y sus ecos en territorio egipcio. Por todo esto, la literatura judía de cuño alejandrino nos ofrece una mirada privilegiada a ese mundo tan ecléctico de los albores del cristianismo9.

en el mundo antiguo. El Negev y sus interacciones con Egipto, Asiria y el Levante en la Edad del Hierro (1200-586 a. C.), Society of Biblical Literature - Centro de Estudios de Historia del Antiguo Oriente (UCA) 2008; M. WRIGHT, "Contacts between Egypt and Syro-Palestine in the Protodynastic Period”, Biblical Archaeology 48 (1985) 240-253.

${ }^{6}$ A. Rosenvasser, "Pharaonic Egypt and Israel in the Light of Isaiah's Oracles against Egypt", Revista del Instituto de Historia Antigua Oriental 3 (1976) 107-125 (124).

7 E. HuzAR, “Alexandria ad Egyptum in the Julio-Claudian Age", ANRW II.10.1 (1988) 619-668 (653).

8 J. GwYn GRIFFITHS, “Egypt and the Rise of the Synagogue”, JTS 38 (1987) 1-15.

9 La escuela judeo-alejandrina, iniciada por Aristóbulo en el siglo ॥ a. C., florecerá con Filón en la primera mitad del siglo । d. C. y continuará en la escuela catequética cristiana de Panteno, Clemente y Orígenes, entre otros; R. PEnNA, Ambiente histórico-cultural de los orígenes del cristianismo, Bilbao 1994, 91. 
Sin embargo, el mapa no está completo y no ha sido suficientemente evaluada la presión que ejerció el culto imperial sobre la vida cotidiana de las comunidades de la diáspora. Durante el período grecorromano, la liturgia imperial fue una herramienta propagandística muy eficaz para legitimar la autoridad del monarca. Un eco de esta presión se puede percibir en la lectura de los capítulos 6 y 7 de 2 Macabeos, donde se puede apreciar cómo el culto imperial fue impuesto hasta en el mismo Templo de Jerusalén, y cómo los judíos eran forzados a celebrar fiestas profanas y respetar las costumbres del calendario litúrgico imperial. Frente a esta presión, Israel desarrolló un tipo de literatura apologética que rechazó esas imposiciones y a su vez llamó a conservar las antiguas tradiciones. Por eso es lógico que varios elementos propios de la liturgia imperial aparezcan en la literatura judía de este período. Goodenough, por ejemplo, estudió la literatura mística del judaísmo alejandrino y propuso influencias de los cultos mistéricos sobre la misma ${ }^{10}$. Su investigación, reevaluada por Lease, revela que existió un fuerte debate religioso en la comunidad alejandrina contra los cultos mistéricos del período grecorromano ${ }^{11}$.

En este período tan globalizador, el diálogo entre las diversas comunidades de la diáspora fue fecundo y prolongado. Las tradiciones de interpretación del Antiguo Testamento particulares de una región pudieron ser conocidas y compartidas por otras comunidades judeo-helénicas lejanas. Tener en mente este fenómeno de interacción cultural y religiosa puede brindarnos algunas claves para comprender mejor el pensamiento joánico.

Teniendo en cuenta los elementos previos, restringiremos nuestro análisis a ciertos elementos particulares del prólogo del cuarto evangelio en lo que respecta a la cosmología, antropología, liturgia y teodicea allí presentes.

\section{El prólogo del evangelio de Juan}

El prólogo del evangelio de Juan es una obra poética que introduce una temática que luego se desarrollará a lo largo del libro. Quizá provenga de un himno preexistente reelaborado con fines litúrgicos y/o didácticos ${ }^{12}$.

10 E. Goodenough, By Light, Light: The Mystic Gospel of Hellenistic Judaism, Yale 1935.

11 G. LEASE, “Jewish Mystery Cults since Goodenough”, ANRW 2.20.2 (1987) 858-880.

12 E. Miller, Salvation History in the Prologue of John, Leiden - New York - Copenhagen - Koln 1989, 96; A. DetTWILER, “Le prologue johannique (Jean 1,1-18)”, La communauté johannique, 185-203 (193); M. GoRdLE, "The Johannine Prologue and Jewish Didactic Hymn Traditions: A New Case for Reading the Prologue as a Hymn", JBL 128 (2009) 781-802. 
Sin embargo, este aspecto litúrgico excede el marco introductorio y recorre todo el evangelio, asociando discursos y acciones de Jesús con varias fiestas judías. De hecho, Borgen considera que el evangelio ha sido elaborado en clave litúrgica, siendo un homiliario de las fiestas del calendario judío ${ }^{13}$. Si se acepta que los vv. 14-28 contienen una confesión de fe comunitaria, el prólogo sería la exposición definitiva de las creencias de las comunidades joánicas redactadas de modo tal que fueran aptas para ser cantadas en $s u$ liturgia ${ }^{14}$. A su vez, el prólogo se presenta como un texto programático que presenta la actividad del Logos relacionándola con categorías tales como vida, luz, gracia y verdad, que permitirán comprender el resto del evangelio. Por eso algunos autores le atribuyen una función similar a la de una obertura lírica ${ }^{15}$.

El Logos joánico es preexistente a la creación y se lo identifica desde el primer versículo con la Palabra creadora divina. Este planteo, con varios puntos de contacto con la personificación de la Sabiduría divina en los textos sapienciales ( $\operatorname{Pr} 8-9$; Sir 24; Sb 10), remite a los relatos de creación bíblicos y también a cosmologías de otras culturas.

Si bien la cosmología del prólogo no es el único tema allí desarrollado, el autor introduce en él su propia reelaboración de la palabra divina siguiendo el planteo de Gn $1{ }^{16}$. Al retomar las palabras év ả $\rho$ ñ̃ con las que comienza el libro de Génesis (LXX) establece un puente temático y lingüístico entre la acción del Logos y la de la palabra divina creadora inmediatamente reconocible por la audiencia judeo-helénica de habla griega. Esta frase $\dot{\varepsilon} v$ ả $\rho \chi \tilde{\eta}$, poco frecuente en la literatura griega contemporánea a la redacción del evangelio, remite al oyente/lector al comienzo de la historia sagrada y retoma los designios divinos allí enunciados ${ }^{17}$.

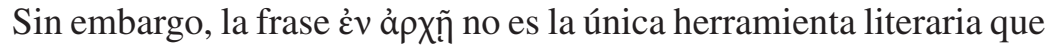
asocia el prólogo con el relato de creación de Gn 1. En su comentario, Boismard cita otras cuatro expresiones comunes entre los primeros ver-

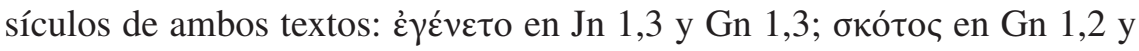

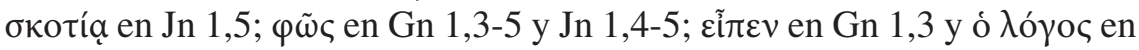
Jn 1,1 .

13 P. Borgen, Bread from Heaven - An Exegetical Study of the Concept of Manna in the Gospel of John and the Writings of Philo, Leiden 1965.

14 G. Beasley-Murray, Word Biblical Commentary-John, 1987, “Prologue”, 1.

15 Ib., 3.

16 T. Evan Pollard, "Cosmology and the Prologue of the Fourth Gospel", Vigiliae Christianae 12 (1958) 147-153.

17 X. LÉon-Dufour, Lectura del evangelio de Juan (Jn 1-4), Salamanca 1984, 55. 
Siguiendo la misma línea, tanto Bedard ${ }^{18}$ como Barrosse ${ }^{19}$ extienden los puntos de contacto de Gn 1 a varios textos del evangelio de Juan.

Por otro lado, Boismard también relaciona diversas fiestas judías mencionadas en los textos joánicos con el primer capítulo del Génesis. Por eso propone una estructura del evangelio que incluye y articula esos motivos:

San Juan ha querido repartir los diferentes episodios de la vida de Cristo según una sucesión de períodos [...] intencionadamente distribuidos a lo largo de siete días, cuyo cómputo es cuidadosamente anotado por la frase "al día siguiente" o "tres días después" [...] Es la primera semana del ministerio mesiánico [...] Pero la división cronológica no para ahí. Es toda la vida de Cristo la que está distribuida según siete épocas diferentes que se refieren a las principales fiestas del calendario judío; muchas de estas fiestas cuentan exactamente una semana.

El mismo autor concluye que esta estructura de siete semanas nos invita a poner el ministerio mesiánico en paralelismo con la obra creadora de los primeros siete días de la creación ${ }^{20}$.

La asociación del prólogo con la primera semana creadora, junto a sus características hímnicas, aportan elementos para pensar que el mismo tendría una función litúrgica específica. Así como los relatos de cosmologías y cosmogonías de otras civilizaciones del antiguo Oriente Medio tenían una función propia para ser recitados al comienzo de sus respectivos calendarios litúrgicos, no es casual que el texto de Gn 1 se haya conservado en la liturgia cristiana para ser proclamado la víspera del Domingo de Resurrección, cuando el motivo de la renovación de la creación es asociado a la celebración de la Pascua. El prólogo, entonces, puede haber sido cantado durante la liturgia de las primeras comunidades joánicas, celebrando la nueva creación en Cristo asociada a su resurrección en un contexto pascual durante el primer mes del calendario judío.

\section{La cosmología y antropología del prólogo y sus similitudes con la literatura egipcia}

Pero las similitudes entre los relatos de Gn 1 y el prólogo se extienden más allá de las planteadas hasta el momento, e incluyen la antropolo-

18 S. Bedard, "The Johannine Creation Account", disponible en www.biblicaltheology.com/Research/BedardSJ03.pdf.

19 T. Barrosse, "The Seven Days of the New Creation in St. John's Gospel”, CBQ 21 (1959) 507-516.

20 M. BoIsmard, El prólogo de Juan, Madrid 1967, 160. 
gía de Gn 1,26-27. En efecto, hay un puente entre cosmología y antropología ya presente en el primer capítulo del libro de Génesis que es retomado al comienzo del evangelio de Juan. Las categorías de imagen y semejanza divina son utilizadas para sustentar la encarnación del Logos y al mismo tiempo afirmar su divinidad y preexistencia. Argumentando de este modo, el evangelio salva la brecha planteada por la literatura sapiencial, que, si bien desarrolló los aspectos personales de la Sabiduría y su acción creadora, no alcanza para sugerir completamente la humanidad del Logos.

Autores como Borgen ${ }^{21}$ y Droge ${ }^{22}$ introducen otro elemento a esta temática común. Planteando similitudes entre los versículos referidos al reposo divino (Gn 2,2-3) y varios textos del evangelio de Juan (cf. Jn $5,9.10 .16 .18 ; 7,22-23 ; 9,14-16 ; 19,31)$, relacionan los textos joánicos con tradiciones interpretativas en debate sobre el reposo divino en el primer sábado de la creación. Es decir, incluyen el descanso sabático como tema reelaborado en los textos joánicos.

Es posible que esta temática sobre el sábado sea una categoría importante para entender la teleología joánica, señalando un elemento de conflicto con el culto sinagogal:

La polémica contra la sinagoga es un importante motivo en el cuarto evangelio, y debemos reconocer que esta batalla no haya sido probablemente peleada en Palestina [...] La actitud de Juan hacia los judíos no es misionera, sino apologética y polémica [...] con el propósito de contrarrestar la propaganda judía más que de convertirlos ${ }^{23}$.

Lo cierto es que las tradiciones interpretativas sobre la primera semana de la creación de Gn 1 encuentran eco en los textos joánicos y no solo remiten a la cosmología y antropología, sino también al debate sobre si la obra creadora del Logos está concluida o no el primer sábado, es decir, incluyen la teleología y la escatología.

Una pregunta que surge entonces es si la síntesis joánica es propia o está reflejando tradiciones interpretativas de Gn 1 previas a la redacción del evangelio, tradiciones que ya tenían elaborados los aspectos mencionados.

21 P. Borgen, “Logos Was the True Light”, NT 14 (1972) 115-130.

22 A. Droge, “Sabbath Work / Sabbath Rest: Genesis, Thomas, John”, History of Religions 47 (2007-2008) 112-141.

${ }^{23}$ R. E. Brown, The Gospel According to John (I-XII), London - Dublin - Melbourne 1971, LXXIII-LXXIV. 


\subsection{Antecedentes en Filón de Alejandría}

En la obra de Filón de Alejandría se elaboran categorías similares a las joánicas durante un período previo a la redacción del cuarto evangelio. Los textos filónicos relacionan la actividad del Logos con la luz primordial, la palabra creadora y la antropología de los vv. 26-27 del libro del Génesis.

En De somnis 1,75 se describe al Logos como modelo sublime y arquetípico de la creación y se lo identifica con la luz primordial. En De confusione linguarum 146-147 se presenta al Logos como la primera Palabra divina con características humanas y a imagen de Dios, describiendo al ser humano como hijos de esta imagen eterna y arquetípica. En Opificio mundi 1,25 se identifica al Logos de Dios con el modelo arquetípico por el cual el hombre fue creado a imagen de Dios. En Opificio mundi 1,31 se identifica la imagen de Dios perfecta, el Logos, con la razón divina, que es fuente de toda luz ${ }^{24}$.

Además, en Legum allegoriarum 31, Filón reelabora la antropología de Gn 2, donde se presenta al ser humano creado no por la palabra divina, sino a partir del barro. Plantea dos tipos de seres humanos, los celestiales y los terrenales. El hombre celestial es imagen de Dios y es incorruptible; el hombre terrenal ha sido "moldeado" de barro, es decir, es creatura. De este modo hay en la obra filónica una síntesis que incluye dos antropologías correspondientes a los relatos de Gn 1 y 2 .

Basten estos ejemplos para ver cómo las tradiciones interpretativas sobre el primer día de la creación y las dos antropologías (Gn 1 y 2) están unidas en la recepción filónica de las tradiciones veterotestamentarias.

\subsection{Posibles antecedentes en Nag Hammadi}

De particular interés para el estudio de las tradiciones joánicas son los textos egipcios que provienen de la colección de Nag Hammadi. En un primer momento fueron catalogados como textos gnósticos, sin embargo son una colección dispar de códices, siendo algunos de redacción previa al evangelio de Juan.

Uno de los textos de Nag Hammadi puesto en relación con el prólogo de Juan es Trimorfa Protennoia (NH XIII,1). Ambos contienen lenguaje y categorías similares, abrevando probablemente en un trasfondo común.

${ }^{24}$ C. H. Dodd, Interpretación del cuarto evangelio, Madrid 1978, 278-279. 
Según Evans, el contexto histórico del prólogo de Juan sería el debate en las sinagogas de la diáspora sobre distintas corrientes interpretativas relacionadas con la literatura sapiencial ${ }^{25}$. Denzey, en cambio, se distancia de las tradiciones sapienciales como clave hermenéutica del prólogo y propone que ambos textos (el prólogo de Juan y Trimorfa Protennoia) son mitos soteriológicos basados en un modo específico y tradicional de leer e interpretar Gn 1. Ambos buscarían finalidades distintas, remitiendo a debates sobre la naturaleza de la revelación al comienzo de la era cristiana. Esta reflexión sobre quién portaba la verdadera imagen divina (cf. Gn 1,26-27) habría influido en la delimitación de las comunidades del judaísmo helénico y su separación respecto de los gentiles ${ }^{26}$.

Por su parte, Pagels aporta otros elementos provenientes del Evangelio de Tomás (NH II,2) y de las Odas de Salomón ${ }^{27}$ (no perteneciente a la colección de Nag Hammadi) para ilustrar sobre un tipo de teología que conecta la creación del hombre con la actividad de la palabra divina en Gn $1^{28}$. El mundo debe ser considerado en referencia al modelo de Gn 1,1-2,4 y, en consonancia, el ser humano debe restaurarse según la imagen de Dios. Esta referencia al Evangelio de Tomás es importante, ya que la redacción del mismo podría ser anterior a la de los textos joánicos y así reflejar una tradición interpretativa previa de Gn $1^{29}$.

De este modo, tanto el Evangelio de Tomás (NH II,2) como otros textos de la colección de Nag Hammadi abrevarían en modos comunes de leer Gn 1 compartidos a su vez con comunidades judeo-helénicas que vivían en Egipto y que leían la LXX a la luz de la filosofía griega, de modo similar al de Filón. A su vez, estas comunidades podrían también estar asociadas a círculos comprometidos con prácticas herméticas ${ }^{30}$.

${ }^{25}$ C. Evans, Word and Glory: On the Exegetical and Theological Background of John's Prologue, Sheffield 1993, 18, 146.

26 N. Denzey, "Genesis Traditions in Conflict?: The Use of Some Exegetical Traditions in the Trimorphic Protennoia and the Johannine Prologue", Vigiliae Christianae 55 (2001) 20-44 (22-23, 42).

27 Por el momento dejamos de lado el análisis de los paralelos con las Odas de Salomón, ya que este sería un texto de origen antioqueno y posterior al evangelio de Juan. Cf. A. Díez Macho (ed.), Apócrifos del Antiguo Testamento, Madrid 1984, 208209.

${ }^{28}$ E. PAGels, "Exegesis of Genesis 1 in the Gospels of Thomas and John", JBL 118 (1999) 477-496 (496).

29 S. Davies, "The Christology and Protology of the Gospel of Thomas", JBL 111 (1992) 663-682 (682).

30 Pagels, “Exegesis of Genesis 1”, 479-480. 
Este tipo de exégesis habría gozado de aceptación en diversos círculos del judaísmo de la diáspora a comienzos de la era cristiana, aflorando, por ejemplo, en los textos paulinos:

Porque lo que de Dios se conoce les es manifiesto, pues Dios se lo manifestó. Porque las cosas invisibles de él, su eterno poder y deidad, se hacen claramente visibles desde la creación del mundo, siendo entendidas por medio de las cosas hechas (Rom 1,19-20).

Este texto paulino relaciona en Cristo la obra creadora divina y su revelación, haciendo "visibles" y "comprensibles" al ser humano las cosas por él creadas. Así enlaza dos formas de concebir la actividad de Cristo: 1) como la manifestación de Dios, y 2) como la luz que ilumina la creación para hacerla comprensible a los hombres. Es decir, que identifica la luz primordial con la actividad creadora de Cristo.

Otro tanto ocurre en los textos joánicos. Desde los primeros versículos del prólogo, y sin que haya ningún desarrollo teológico al respecto, se identifica al Logos con la luz primordial. Se entiende que el lector/oyente no necesita explicaciones al respecto y, por tanto, la identificación de la palabra divina con el Logos y la luz primordial pareciera ser algo aceptado. Sin embargo, en Gn 1 la luz es creada por la palabra divina. Entonces, ¿cómo se pasa a identificar la luz con la Palabra increada y divina?

Una clave interpretativa estaría presente en el posible juego de palabras en la Biblia griega entre dos términos similares, $\varphi \tilde{\omega} \varsigma$, "luz", y $\varphi \omega ́ \varsigma$, "hombre" 31 . Una hermenéutica que intercambiara uno por otro en la recepción del texto griego de Gn 1,3-5 permitiría este tipo de interpretación. Este tipo de juego de palabras habría sido inmediatamente percibido por las comunidades judeo-helénicas de la diáspora, tendiendo un puente lingüístico entre la palabra divina y la luz primordial.

Veamos cómo algunos dichos del Evangelio de Tomás reflejan esta misma línea interpretativa:

77. Dijo Jesús: “Yo soy la luz que está sobre todos ellos. Yo soy el universo: el universo ha surgido de mí y ha llegado hasta mí. Partid un leño y allí estoy yo; levantad una piedra y allí me encontraréis" $\left(46_{22-28}\right)^{32}$.

En este pasaje, Jesús se identifica a sí mismo con la luz y la actividad creadora de la palabra divina, dos elementos presentes en Gn 1 y Jn 1. Sin embargo, en el Evangelio de Tomás esta luz es una luz primordial, preexistente a la creación, que habla en primera persona. Es decir, hay una identi-

31 Droge, "Sabbath Work", 125.

32 A. de Santos Otero, Los evangelios apócrifos, Madrid 2005, 381. 
ficación de Jesús con esa luz primordial ${ }^{33}$. Davies interpreta esta luz como una capacidad inherente al ser humano de percibir el mundo como Reino de Dios. El autor articula las categorías de origen, Reino de Dios, la actividad de Jesús y la luz primordial como términos equivalentes entre sí, que el Evangelio de Tomás reelabora siguiendo Gn 1,3-4 ${ }^{34}$.

Otro tanto ocurre en los logia 50a, 83 y 84 del Evangelio de Tomás, donde la luz primordial se asocia con la naturaleza humana, creada a imagen de Dios (cf. Gn 1,26-27). Es decir, se suma un elemento antropológico a la identificación de Jesús con la luz primordial:

83. Dijo Jesús: “Las imágenes se manifiestan al hombre, y la luz que hay en ellas permanece latente en la imagen de la luz del Padre. Él se manifestará, quedando eclipsada su imagen por su luz" (47, $19-24$ ).

84. Dijo Jesús: "Cuando contempláis lo que se os parece, os alegráis; pero cuando veáis vuestras propias imágenes hechas antes que vosotros -imperecederas y a la vez invisibles-, ¿cuánto podréis aguantar?" $\left(4_{24-29}\right)^{35}$.

Según este tipo de exégesis, lo que se percibe del mundo solo puede ser visto por medio de la luz primordial, Jesús, quien a su vez es imagen de la luz del Padre. De este modo, el ser humano no podría contemplar su propia imagen sino a través de Cristo, la luz del Padre ${ }^{36}$.

En otro texto conocido como el Escrito sin título, o también Sobre el origen del mundo (NH II,5 y XIII,2), se describe al hombre primordial como preexistente, es decir, previo a la creación de todas las cosas, surgido a la existencia en el día primero, a diferencia del Adán psíquico, que surgió en el sexto día. Se establece una diferencia entre el hombre primordial (Jesús) y el hombre psíquico (el ser humano). Y otro tanto ocurre en el texto de Eugnostos (NH III,2 y V,1), también datado en los comienzos del siglo I d. C y, por tanto, previo a los textos joánicos. Allí se identifica al Padre autoengendrado como "Adán de luz" (III,81) $)^{37}$.

Según Pagels, el evangelio de Juan entraría en polémica contra este tipo de interpretación, organizando un discurso en tres etapas. Las tres negaciones introducidas en el prólogo plantean el rechazo de las tinieblas a la luz primordial. En la primera negación, las tinieblas no recibieron dicha luz, el Logos (Jn 1,5). En la segunda (1,9-10), el mundo no la reconoció,

33 Pagels, "Exegesis of Genesis 1", 484.

34 Davies, "The Christology and Protology", 665.

35 Santos Otero, Los evangelios apócrifos, 382.

36 Davies, "The Christology and Protology", 669.

37 The Nag Hammadi Library in English, Leiden - Köln - New York 1996, 232. La traducción es nuestra. 
pese a que el mundo fue hecho por dicha luz. Y, en la tercera, esa luz vino a los suyos y los suyos no la recibieron (Jn 1,11). De este modo, el evangelista afirma la divinidad del Logos y al mismo tiempo su identificación con la luz primordial, rechazando a quienes no creen en su encarnación ${ }^{38}$.

Otro tema común entre los evangelios de Juan y Tomás versaría sobre la conclusión de la creación y el descanso sabático. La recepción de Gn 2,2 en Evangelio de Tomás presupone un estado de la creación congruente con el del reposo sabático, es decir, la creación como culminada el primer viernes y en reposo el sábado. En cambio, en el evangelio de Juan las tinieblas todavía no han sido completamente vencidas y, por tanto, la actividad del Logos no está concluida, Jesús no reposa en sábado, como tampoco lo hace el Padre. Algunos ejemplos de esta actividad divina sabática son la curación del paralítico en sábado (cf. Jn 5,17) y la curación del ciego de nacimiento, realizada también en sábado (cf. Jn 9,14).

Pero ¿de dónde proviene esta interpretación de la actividad divina en sábado? Remitámonos por el momento al texto hebreo de Génesis en que Dios culminó su obra el séptimo día y en él cesó su obra creadora:

Y acabó Dios en el día séptimo la obra que hizo; y reposó el día séptimo de toda la obra que hizo (Gn 2,2).

El texto hebreo es ambiguo y describe dos acciones en el séptimo día: cesar la obra creadora y reposar. Deja abierta la posibilidad de que Dios realizara el sábado algún tipo de "obra". Esta ambigüedad del texto hebreo probablemente haya originado algún tipo de polémica en torno a la actividad divina en sábado y la prescripción del reposo sabático. Sin embargo, el texto griego de Gn 2,2 no da lugar a la polémica, ya que dice expresamente que la creación culminó en el sexto día y en el séptimo Dios reposó. En cambio el Targum Neófiti sigue más fielmente el texto masorético de Gn 2,2: "Y en el séptimo día la Memrá del Señor terminó su trabajo que había creado".

Vemos entonces que el evangelio de Juan sigue una tradición que interpreta la obra creadora y el reposo del sábado de un modo no acorde al texto griego, sino más afín a una posible recepción del texto hebreo.

El mismo tipo de debate se percibe en la recepción que el Evangelio de Tomás hace sobre el reposo divino en el primer sábado de la creación:

50. Dijo Jesús: “Si os preguntan: ¿¿De dónde habéis venido?’, decidles: ‘Nosotros procedemos de la luz, del lugar donde la luz tuvo su origen por sí misma; [allí] estaba afincada y se manifestó en su imagen'. Si os preguntan: ¿Quiénes sois vosotros?', decid: 'Somos sus hijos y somos los elegidos del

38 Pagels, “Exegesis of Genesis 1", 481. 
Padre viviente'. Si se os pregunta: ‘Cuál es la señal de vuestro Padre que lleváis en vosotros mismos?', decidles: 'Es el movimiento y a la vez el reposo'" $\left(41_{30}-42_{7}\right)^{39}$.

Comentando este logion, Davies afirma que, como los siete días de la creación comienzan con el movimiento del Espíritu sobre las aguas y culminan con el reposo del sábado, el "origen" debe ser entendido a la vez como movimiento y reposo. Por tanto, si la humanidad está en su estado de “origen", la señal que la humanidad porta del Padre es movimiento y reposo, en esa secuencia. La cristología del Evangelio de Tomás seguiría entonces la lógica de un reposo sabático ${ }^{40}$.

También Droge comenta el mismo logion 50 y propone que, en el Evangelio de Tomás, Jesús vino a informar al ser humano sobre su posibilidad de actualizar la luz primordial. Los que así lo hacen perciben el mundo y a sí mismos en la condición del sábado. Es decir, "han sido restaurados en su estado primordial andrógino de dominio y reposo inmortal", son imágenes de Dios. En esta propuesta utópica sobre el Reino de Dios, donde todo ya ha sido concluido el primer sábado y no habría espacio para la religión: "Lo que el Evangelio de Tomás proclama es nada menos que el fin de la religión" ${ }^{41}$. Si todo está concluido, no hay peregrinar posible, no hay tensión escatológica.

Frente a esta interpretación del Evangelio de Tomás sobre el descanso sabático, el evangelio de Juan propondría otra cristología donde la creación todavía es una obra que tiene que ser culminada en un sábado que abarca toda la historia. Es decir, una obra todavía no concluida. Las tinieblas no han sido totalmente reducidas, y solo a quienes reciben al Logos, la luz primordial, se les da la capacidad de ser hijos de Dios (cf. Jn 1,9-12). El Logos joánico continúa trabajando, y el reposo sabático todavía no ha llegado. La cristología joánica compromete al ser humano con la obra creadora del $\operatorname{Logos}^{42}$.

Reuniendo las evidencias planteadas en los dos últimos puntos se puede apreciar que la recepción de las tradiciones de Gn 1-2 fue prolífica en suelo egipcio. En efecto, tanto los textos filónicos (relacionados con el judaísmo alejandrino) como los textos de Trimorfa Protennoia, el Escrito sin título, Eugnostos y el Evangelio de Tomás de la colección de Nag Hammadi (que también proviene de suelo egipcio), todos ellos elaboran

\footnotetext{
39 Santos Otero, Los evangelios apócrifos, 378.

40 Davies, "The Christology and Protology", 670.

41 Droge, "Sabbath Work", 126.

42 Ib., 128.
} 
categorías presentes en Gn 1-2 como así también en los textos joánicos, siendo sin embargo previos al cuarto evangelio.

Surgen entonces algunas preguntas: ¿por qué en suelo egipcio abunda más este tipo de literatura que elabora categorías comunes con los textos joánicos? ¿Estará esto relacionado con la recepción en suelo egipcio de tradiciones interpretativas propias de Gn 1-2? ¿O quizá la hermenéutica egipcia de Gn 1-2 tenga más elementos comunes con el pensamiento egipcio de los supuestos hasta ahora?

\section{Elementos de Gn 1-2 que reflejan la cosmología y antropología bíblicas en debate con Egipto}

La mayoría de los comentaristas bíblicos han aceptado sin suficiente espíritu crítico la presencia de elementos comunes entre los relatos de creación bíblicos y los relatos babilónicos Enuma elish y Atrahasis. Sin embargo son varios los asiriólogos de renombre que han desestimado estas relaciones por ser demasiado vagas. Hoffmeier cita al respecto a Lambet, Millard, Kinnier Wilson y Heidel ${ }^{43}$.

En oposición a la postura "babilónica" han surgido varias voces que proponen vínculos más estrechos entre los relatos de creación egipcios y los narrados en los textos bíblicos de Gn 1-244. Varios autores proponen que, desde el comienzo, los textos de Gn 1-2 reflejarían un debate con la antigua religión egipcia. Según Parrott, esta dialéctica entre la religión hebrea y la egipcia se habría reflejado posteriormente en los textos de Nag Hammadi ${ }^{45}$.

En efecto, desde el siglo XIX son varios los autores que han estudiado las relaciones entre los relatos de creación egipcios y los bíblicos.

43 J. Hoffmeler, “Some Thoughts on Genesis 1 \& 2 and Egyptian Cosmology”, Journal of the Ancient Near Eastern Society 15 (1983) 39-49 (40).

44 A. SAYCE, "The Egyptian Background of Genesis I," en Studies Presented to F. Ll. Griffith, London 1932, 421; A. YAHUDA, The Accuracy of the Bible, London 1934; ID., The Language of the Pentateuch in Its Relation to Egyptian, London 1933; C. H. Gordon, "Khnum and El", en S. Israelit-Groll (ed.), Scripta Hierosolymitana: Egyptological Studies, vol. 28, Jerusalem 1982; Hoffmeler, “Some Thoughts”; T. Shetter, “Genesis 1-2 in Light of Ancient Egyptian Creation Myths" lartículo presentado durante la Student Academic Conference del Dallas Theological Seminary, 18 de abril de 2005); G. Johnston, "Genesis 1 and Ancient Egyptian Creation Myths", Bibliotheca Sacra 165 (2008) 178-194.

45 D. Parrott, “Gnosticism and Egyptian Religion”, Novum Testamentum 27 (1989) 73-93 (93). 
En 1887, Sayce planteó paralelos entre los relatos de creación de la teología de Hermópolis y los relatos de Gn 1, y propuso al menos cuatro elementos comunes entre ellos: 1) el caos primordial; 2) el aliento divino sobrevolando las aguas (en un caso, del dios Amón, y en el otro, de Elohim); 3) la creación de la luz, y 4) el emerger de una colina por sobre las aguas primordiales ${ }^{46}$. Posteriormente, entre 1933 y 1934, Yahuda extendió las relaciones a otros textos del Pentateuco ${ }^{47}$. En 1982, Cyrus Gordon incluyó entre las similitudes de los relatos egipcios y hebreos de creación del hombre: en el ámbito egipcio, el dios Khnum moldea como alfarero al ser humano, de modo similar al modo en que YHWH Elohim crea al ser humano en Gn 2,6-748.

En 1983, Hoffmeier identificó varios paralelos entre la cosmología de Hermópolis y la bíblica de Gn 1, estableciendo relaciones etimológicas que remiten al comienzo de la creación utilizando el término "cabeza" (en hebreo y tp en egipcio). Este autor relaciona el grupo de dioses de la Ogdóada egipcia, Nun, Keku, Hehu y Amun, con los términos he-

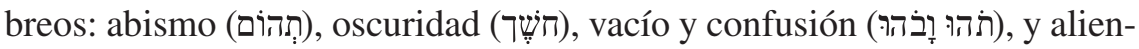
to divino (רוּה הֶלֶהים). Incluye también paralelos entre los relatos de creación del ser humano y cita el texto egipcio de la Sabiduría de Merikare, del siglo $\mathrm{x}$ a. C., donde se menciona que el dios Ra da vida al ser humano a su imagen e insuflando aliento en su nariz (Merikare 132-134) ${ }^{49}$. Tomemos este último texto como ejemplo ilustrativo:

Pastorea a su pueblo, el rebaño de Dios. Porque en su favor creó el cielo y la tierra, estableció los límites de las aguas y creó el viento para que sus narices pudieran vivir. Ellos son su imagen, engendrados de su cuerpo, y es en su favor que se levanta en el cielo. Pues él creó plantas, ganado, rebaños y pescados para mantenerlos (Merikare 132-134) ${ }^{50}$.

Hoffmeier concluye que los relatos de creación bíblicos (Gn 1-2) fueron redactados con fines apologéticos contra la religión egipcia, particularmente la de Hermópolis.

Más recientemente, Tony Shetter sumó más elementos que relacionan las cosmologías egipcia y hebrea. Comparó los relatos de creación de los tres tipos de teologías egipcias, la de Heliópolis, la de Hermópolis y la de Menfis ${ }^{51}$.

\footnotetext{
46 SAYCE, "The Egyptian Background”, 421.

47 Yahuda, The Accuracy of the Bible; ID., The Language of the Pentateuch.

48 Gordon, "Khnum and El".

49 Hoffmeier, "Some Thoughts", 43, 47.

50 W. Simpson, The Literature of Ancient Egypt, New Haven - London 2003, 164.

51 Shetter, "Genesis 1-2".
} 
Para ilustrar, veamos un texto de la teología menfita en la que el dios Ptah realiza su obra creadora mediante la palabra. En una inscripción sobre granito negro proveniente del templo dedicado al dios Ptah en Menfis, conocida como Piedra Shabaka (BM 498), se puede leer:

Hubo una evolución en la imagen de Atón, tanto en su corazón como su lengua. Grande e importante es Ptah, quien dio vida a todos los dioses y asimismo a sus ka mediante su corazón y su lengua (Teología menfita 1.15 col. 53).

En este texto, el dios Ptah es previo a todas las fuerzas y elementos creados. Él está en el origen de la creación, representando la mente y los designios divinos del dios Atón ${ }^{52}$. En el texto se puede apreciar el poder creador de la palabra divina en la cosmología egipcia, elemento totalmente ausente en la babilónica. Shetter propone que los textos bíblicos polemizan contra los mitos egipcios, y un signo de ello es la creación de la luz en el primer día, separada de la creación de las luminarias en el día cuarto. El relator bíblico se distancia de la concepción egipcia, donde el dios creador es identificado con la luz solar, y designa, en cambio, al sol y la luna como simples "luceros" con funciones específicas, subordinando la creación de los mismos a la capacidad creadora de la palabra divina (cf. Gn 1,14-19).

El autor plantea además algunos paralelos entre el relato de creación del ser humano según Gn 2,6-7 y el relato egipcio por el que el dios Khnum moldea las figuras de los hombres y animales en su rueda de alfarero con el barro del Nilo, y luego su diosa consorte Heket insufla en las narices de las imágenes el aliento de vida, simbolizado con el ankh, haciendo que ellas surjan a la vida ${ }^{53}$. En ambos relatos aparece el concepto de "aliento de vida" para describir el principio vital insuflado en la figura de barro. Mientras los relatos de creación de Heliópolis, Menfis y Hermópolis se focalizan en la creación del mundo en general, la tradición reflejada en el relato de Khnum se orienta específicamente en la creación del ser humano y presenta similitudes notables con el relato bíblico de Gn 2,6-7. Sin embargo, hay también diferencias evidentes entre ambos. En el relato egipcio hay involucrados dos dioses en la creación del ser humano, mientras que en el relato hebreo es evidente la intención de atribuir toda la obra creadora a YHWH Elohim.

Dado que en la mitología egipcia los relatos de creación del mundo están separados de los relatos de creación del ser humano, y en cada uno de ellos la forma de creación es distinta, los dos relatos hebreos de creación (Gn 1 y 2) serían sendas respuestas a los mitos egipcios. Cada relato hebreo

52 W. Hallo - K. Lawson, The Context of Scripture I, Leiden - Boston 2003, 22.

${ }_{53}$ G. HART, The Routledge Dictionary of God and Goddesses, London - New York $2005,86$. 
debate con los dos principios creadores egipcios, la palabra en Gn 1 y el alfarero divino en Gn 2. Siguiendo esta línea argumentativa, Shetter concluye que los relatos de creación hebreos tienen más afinidad con los egipcios que con la cosmología babilónica ${ }^{54}$.

También Johnston, siguiendo la línea de Shetter y Hoffmeier, aporta similitudes y diferencias entre las cosmologías egipcia y hebrea: 1) frente a los relatos de origen de los dioses egipcios, la cosmología hebrea rechaza cualquier noción de cosmogonía y presenta a YHWH como preexistente a la creación y único creador; 2) la cosmología hebrea rechaza además cualquier atisbo de panteísmo, la obra creada es distinta de su creador, no hay deificación de la naturaleza; 3) la versión Yahvista de la creación es claramente monoteísta; 4) el culmen de la creación en el relato hebreo no es la generación del sol a imagen del dios solar, como en el ámbito egipcio, sino la creación del ser humano a imagen y semejanza del Dios de Israel; 5) el marco característico de siete días de Gn 1 rechaza el paradigma de la recreación diaria del relato egipcio, donde el dios solar renace cada mañana.

Poniendo énfasis en estas diferencias, Johnston concluye que Gn 1 parece ser una obra literaria orientada a refutar los relatos de creación de las cosmogonías de Cercano Oriente en general, y en especial contra la antigua mitología de creación egipcia. Es decir, Gn 1 no fue compuesto originalmente como un tratado científico, sino en polémica contra los modelos egipcios de creación que competían con el yahvismo ${ }^{55}$.

Vemos, por tanto, que ya existía en los dos primeros capítulos del libro del Génesis una intención de polemizar con los mitos de creación de otras culturas, pero especialmente con la religión egipcia. Esta polarización contra Egipto en las cosmologías bíblicas explicaría algunos aspectos de la recepción posterior de Gn 1 y 2 en suelo egipcio, y por qué es allí donde más se elaboró un tipo de literatura que reflejó ese debate. El judaísmo de Egipto era el más capacitado para reconocer e interpretar el debate histórico contra Egipto, y por ello fue el más proclive para actualizarlo en sus desarrollos teológicos.

\section{La incidencia del culto imperial}

Hubo además otro elemento que pudo haber incidido en la proliferación de las antiguas tradiciones interpretativas de Gn 1 y 2: la presión ejer-

\footnotetext{
54 Shetter, “Genesis 1-2", 9-10.

55 Johnston, “Genesis I”, 194.
} 
cida por el culto imperial. Si bien esta presión ya se había hecho sentir en los siglos previos al comienzo del cristianismo (cf. 2 Mac 6-7), aumentó su intensidad con el correr de los siglos. ¿Por qué detenernos un momento en este tema? Porque es justamente en el culto imperial donde se celebran los atributos divinos del emperador y se actualiza y restaura la obra creadora de los dioses.

Herederas como eran del monoteísmo hebreo, debió de haber sido muy provocativo para las primeras comunidades cristianas verse obligadas a adorar a un rey que pretendía ser divino y en cuyo beneficio había que realizar sacrificios. Desde sus orígenes, el cristianismo celebraba el valor sacrificial de la muerte de Cristo, actualizándolo en la eucaristía, y esa práctica provocó enfrentamientos con los sacrificios paganos ${ }^{56}$. Pero más provocativo aún debió de haber sido para las comunidades joánicas, para las que $s u$ rey (cf. Jn 18,17) era de naturaleza divina y humana, y su culto, en "espíritu y verdad" (cf. Jn 4,4). Por ello, para las primeras comunidades cristianas, pero especialmente para las comunidades joánicas, el debate precedente no parece haber quedado restringido al ámbito de la cosmología y antropología, sino que abarca también el culto. En efecto, al contextualizar el prólogo en un ambiente donde el culto al emperador estaba vigente y su figura debía ser venerada como divina, los debates previos adquieren nuevas aristas.

La administración romana fue la más interesada en sostener el culto imperial, dando privilegios especiales a los sacerdotes y prelados que se avinieran al mismo, y de este modo el culto imperial estuvo vigente durante siglos. Pero fue a partir del reinado de Augusto (63 a. C. - 14 d. C.) cuando el culto al emperador se consolidó como una expresión rutinaria de fidelidad a Roma. Es decir, durante la redacción de los textos joánicos, el culto imperial estaba ya consolidado ${ }^{57}$. El eje central de ese culto era venerar a los emperadores al modo en que se veneraba a los dioses. La lealtad al Estado se expresaba en el culto, su incumplimiento era severamente castigado y su vigencia estaba extendida a lo largo y ancho del Imperio romano ${ }^{58}$.

Hay testimonios arqueológicos y epigráficos del culto imperial en Asia Menor, y más específicamente en Éfeso, Esmirna, Pérgamo y Laodi-

56 S. PrICE, "Between Man and God: Sacrifice in the Roman Imperial Cult", The Journal of Roman Studies 70 (1980) 28-43 (36).

57 Z. MAgYaR, “Imperial Cult and Christianity”, Acta Archaeologica Academiae Scientiarum Hung. 60 (2009) 385-395 (385-386).

58 D. JONES, "Christianity and the Roman Imperial Cult", ANRW 2.23.2 (1980) 1023-1054 (1034). 
cea. Es decir, el culto imperial está testimoniado en varias ciudades relacionadas con los círculos joánicos que dieron origen al libro del Apocalipsis. En estas ciudades existían templos dedicados al emperador, y en ellos se ofrecían sacrificios e himnos, probablemente precedidos por procesiones y concluidos con banquetes ${ }^{59}$. El rechazo del culto imperial por parte de las comunidades mencionadas habría sido uno de los elementos que forjó su identidad, anunciando las persecuciones que les sobrevendrían en el futuro y alentando a sus fieles a sostener su fe aun a costa del martirio ${ }^{60}$.

Sin embargo, en Egipto, las comunidades del judaísmo helénico ya tenían siglos de enfrentamiento contra una ideología real que usaba la religión egipcia como una forma eficaz de imponer esa ideología real. En la liturgia oficial egipcia, sus reyes actualizaban lo que sucedía en el ámbito divino, encarnando al dios solar Ra. El combate cotidiano del dios Sol contra las tinieblas, venciendo al alba y haciendo surgir la vida con su luz matinal, todo era actualizado en los ritos de los templos, ya fuese diariamente por los sacerdotes o por los reyes en determinadas fiestas del calendario litúrgico egipcio. Pero esto se agravó en el período grecorromano, cuando el culto imperial fue impuesto por Roma en Egipto a partir de la época de Octavio y continuó activo hasta el siglo IV d. C. Se reconstruyeron templos y se solventó el culto con aportes administrativos ${ }^{61}$. La ideología real egipcia fue sostenida en el culto con pocas modificaciones, siendo el sumo sacerdote egipcio un oficial romano ${ }^{62}$.

Como ejemplo ilustrativo de esta ideología real expresada en el culto presentamos un texto grabado en el vestíbulo central del templo de Horus, en Edfu, datado en la época ptolemaica, y en cuyos frisos se pueden observar los detalles de los rituales que allí se realizaban ${ }^{63}$ :

Gloria a ti, el Behdetita, Señor del cielo, el noble disco alado que brilla en el horizonte, el hermoso disco solar que ilumina la oscuridad. El noble niño que ilumina los bancos, iris del Ojo de Ra que alumbra las Dos Tierras con

59 K. Cukrowskl, "The Influence of the Emperor Cult on the Book of Revelation", Restoration Quarterly 45 (2003) 51-64 (63).

60 A. DE SILVA, “The Revelation to John: A Case Study in Apocalyptic Propaganda and the Maintenance of Sectarian Identity", Sociological Analysis 53 (1992) 375-395.

${ }^{61}$ G. Dundas, "Augustus and the Kingship of Egypt”, Zeitschrift für Alte Geschichte 51 (2002) 433-448.

${ }^{62}$ W. OCKLE, "State Archives in Graeco-Roman Egypt from 30 BC to the Reign of Septimius Severus", The Journal of Egyptian Archaeology 70 (1984) 106-122 (109).

${ }^{63}$ Este templo fue inaugurado en el siglo ॥ a. C. y estuvo activo hasta finales del Iv d. C; A. Gaber, The Central Hall in the Egyptian Temples of the Ptolemaic Period ltesis doctoral), Durham 2009, 485. 
sus rayos... Horus, que se muestra a sí mismo en el cielo, que rocía la tierra con los rayos de su disco solar. Un hombre anciano en la oscuridad, un niño joven en la mañana, el dios único, Señor de todos los dioses. El que es concebido todos los días en su loto, el que ilumina la tierra, el que se muestra a sí mismo en el horizonte, levantándose por el este todos los días en su cuerpo de Ra, entrando en el oeste en su cuerpo de Ra.

La lectura de este texto permitía a quien lo recitase actualizar el renacimiento diario del dios Ra con sus poderes renovados después de su viaje nocturno. Este renacer cotidiano en el culto garantizaba la vitalidad y prosperidad del rey ${ }^{64}$.

Frente a este culto imperial, la lectura de los textos de Gn 1-2 en las sinagogas egipcias debe de haber suscitado ecos particulares. Por eso en territorio egipcio se hacen más evidentes los contrastes. Los debates contra la antigua religión egipcia, ya contenidos en los dos primeros capítulos de Génesis, se tornan más evidentes ante los ritos oficiales que actualizaban cotidianamente el poder creador del dios Sol y del rey divinizado. Las antiguas tradiciones interpretativas de de Gn 1-2 adquieren un significado relevante frente al culto imperial egipcio, y esto aporta otro elemento para explicar por qué el debate sobre Gn 1 y 2 continuó durante siglos y fue especialmente prolífico en Egipto.

Vemos entonces que ya desde los albores del cristianismo la vigencia del culto imperial no pudo pasar inadvertida para las comunidades judeo-helénicas de Antioquía, Palestina y también para las de Egipto. Si bien en Asia Menor los enfrentamientos debieron de estar más polarizados en torno al tema sacrificial, es muy probable que las comunidades joánicas percibiesen los elementos egipcios presentes en el culto imperial y también elaborados en el sincretismo de los cultos mistéricos. Hay evidencia de esos cultos en el teatro de Éfeso durante el período romano ${ }^{65}$. Frente a las creencias desplegadas en los rituales imperiales, la comunidad joánica responde con su prólogo.

64 El apelativo "Epífanes”, utilizado en la titulatura real ptolemaica y antioquena, remite a la manifestación de lo divino por parte de los reyes en el culto; J. MoRgENSTERN, "The King-God among the Western Semites and the Meaning of Epiphanes", VT 10 (1960) 138-197.

65 C. Bonnet, Religions orientales - culti misterici: neue Perspektiven, Stuttgart 2006,56 . 


\section{Conclusiones}

En el recorrido previo se pudo apreciar cómo los textos de Gn 1 y 2 tienen similitudes con la religión egipcia. La creación por la palabra, la luz primordial, el ser humano creado a imagen y semejanza divinas, moldeado del barro y con aliento de vida, son algunos elementos comunes entre los textos egipcios y los textos hebreos. Y son justamente los elementos comunes con la cosmología egipcia los que afloran posteriormente en la cristología joánica. Solo en la cosmología egipcia la obra creadora se asocia a la palabra divina, como el Logos joánico y como la palabra divina de Gn 1. Asimismo, solo en el ámbito egipcio la luz primordial increada asociada al dios Sol hace surgir a la existencia y da vida, mientras que, en los textos joánicos, el Logos es la luz y el origen de la vida. Por ello son justamente las comunidades judeo-helénicas de Egipto, capaces de comprender, conservar y transmitir estas tradiciones, las que pueden desarrollar más prolíficamente un tipo de literatura que continuara con el debate previo. La obra filónica es un ejemplo de este tipo de ejercicio.

Siguiendo esta lógica, la literatura de Nag Hammadi desarrolla un debate de características propias, pero también influido por la religión egipcia. Produce textos contemporáneos de Filón, pero no necesariamente alineados con el judaísmo. Parrott sostiene que es difícil imaginar que la religión egipcia no haya desarrollado un papel importante en las tradiciones conservadas en Nag Hammadi ${ }^{66}$.

En un mundo tan cosmopolita como el de los albores del cristianismo, las tradiciones se comparten y se cierran filas contra lo que atente contra la fe de Israel. La comunidad judeo-helénica de Alejandría ya estaba entrenada en este tipo de hermenéutica de los textos veterotestamentarios. Y la comunidad de Éfeso probablemente también estuviera familiarizada con una recepción de Gn 1 y 2 que conservase la antigua apologética contra la religión egipcia. Todo ello intensificado por la presión ejercida por el culto imperial.

Si bien la literatura sapiencial ha conservado algunos elementos egipcios, los mismos no eran suficientes para desarrollar una teología del Logos que pudiera abrazar completamente su humanidad y su divinidad. Pero, abrevando en un tipo de hermenéutica de Gn 1 y 2, ejercitada durante siglos y que enlazaba categorías cosmológicas y antropológicas, la teología joánica fue capaz de elaborar una cristología propia superadora con 73-93.

66 D. Parrott, “Gnosticism and Egyptian Religion”, Novum Testamentum 27 (1989) 
un lenguaje acorde al mundo cosmopolita que le tocó enfrentar. Ese Jesús descripto en los textos joánicos es tan divino como la Palabra creadora y tan humano como los hombres creados a su imagen y semejanza. Por eso el Logos joánico es tan cercano al judaísmo helénico alejandrino como a las tradiciones hebreas que lo configuraron. Fue tarea de las primeras comunidades joánicas sostener esta fe en un contexto donde el culto imperial desafiaba sus creencias. La confesión de fe del prólogo proclama en $s u$ himno que la creación todavía no había concluido y que las tinieblas todavía enfrentaban a la luz que vino a los suyos.

Olga Gienini

\section{BIBLIOGRAFÍA}

Barrett, C. K., The Gospel According to St. John, London 1955.

Barrosse, T., "The Seven Days of the New Creation in St. John's Gospel”, $C B Q$ 21 (1959) 507-516.

Beall, T., "Contemporary Hermeneutical Approaches to Genesis 1-11", en T. Mortenson - T. Ury (eds.), Coming to Grips With Genesis: Biblical Authority and the Age of the Earth, New Leaf 2008, 131-162.

Beasley-Murray, G., Word Biblical Commentary - John, Library of Congress Cataloging in Publication Data, 1987.

BeCKer, J., Das Evangelium nach Johanes, I-II, Gütersloh - Würzburg 19791981.

Bedard, S., "The Johannine Creation Account", disponible en www.biblicaltheology.com/Research/BedardSJ03.pdf.

BeutLer, J., "Méthodes et problèmes de la recherche johannique aujourd'hui", La communauté johannique et son histoire, Genève 1990, 15-38.

Bonnet, C., Religions orientales - culti misterici: neue Perspektiven, Stuttgart 2006.

Boismard, M.-E., El prólogo de Juan, Madrid 1967.

Boismard, M.-E. - Lamouille, A., Synopse des quatre évangiles en français, Paris 1977.

Borgen, P., Bread from Heaven. An Exegetical Study of the Concept of Manna in the Gospel of John and the Writings of Philo, Leiden 1965.

-, "God's Agent in the Fourth Gospel", en J. Newsner (ed.), Religions in Antiquity - Essays in Memory of Erwin Ramsdell Goodenough, Leiden 1968, 137-148.

-, "Logos Was the True Light", NT 14 (1972) 115-130.

-, "Moses, Jesus, and the Roman Emperor, Observations in Philo's Writings and the Revelation of John", Novum Testamentum 38 (1996) 145-159.

-, The Gospel of John: More Light from Philo, Paul and Archaeology, Leiden 2014. 
Boyarin, D., "The Gospel of the Memra: Jewish Binitarianism and the Prologue to John", HTR 94 (2001) 243-284.

Brown, R. E., The Gospel According to John, I-II, New York 1966.

-, The Community of the Beloved Disciple, New York 1979.

-, An Introduction to the Gospel of John, New York 2003.

Burge, G., The Anointed Community. The Holy Spirit in the Johannine Tradition, Grand Rapids 1987.

Comfort, P. - Hawley, W., Opening the Gospel of John, Wheaton 1994.

Cukrowski, K., "The Influence of the Emperor Cult on the Book of Revelation", Restoration Quarterly 45 (2003) 51-64.

Davies, S., "The Christology and Protology of the Gospel of Thomas", JBL 111 (1992) 663-682.

Denzey, N., "Genesis Traditions in Conflict?: The Use of Some Exegetical Traditions in the Trimorphic Protennoia and the Johannine Prologue", Vigiliae Christianae 55 (2001) 20-44.

De Silva, A., "The Revelation to John: A Case Study in Apocalyptic Propaganda and the Maintenance of Sectarian Identity", Sociological Analysis 53 (1992) 375-395.

DetTwiler, A., "Le prologue johannique (Jean 1,1-18)", La communauté johannique et son histoire, Genève 1990, 185-203.

Díez Macho, A. (ed.), Apócrifos del Antiguo Testamento, Madrid 1984.

DodD, C. H., Historical Tradition in the Fourth Gospel, Cambridge 1963.

-, Interpretación del cuarto evangelio, Madrid 1978.

Droge, A., "Sabbath Work / Sabbath Rest: Genesis, Thomas, John", History of Religions 47 (2007-2008) 112-141.

Dundas, G., "Augustus and the Kingship of Egypt", Zeitschrift für Alte Geschichte 51 (2002) 433-448.

Evan Pollard, T., "Cosmology and the Prologue of the Fourth Gospel”, Vigiliae Christianae 12 (1958) 147-153.

Evans, C., "On the Prologue of John and the Trimorphic Protennoia", NTS 27 (1981) 95-401.

-, Word and Glory: On the Exegetical and Theological Background of John's Prologue, Sheffield 1993.

Feuillet, A., El prólogo del cuarto evangelio, Madrid 1971.

Goodenough, E., By Light, Light: The Mystic Gospel of Hellenistic Judaism, Yale 1935.

-, "John a Primitive Gospel”, JBL 64 (1945) 145-182.

Gordon, C., "Khnum and El”, en S. Israelit-Groll (ed.), Scripta Hierosolymitana: Egyptological Studies, Jerusalem 1982.

Gordley, M., “The Johannine Prologue and Jewish Didactic Hymn Traditions: A

New Case for Reading the Prologue as a Hymn”, JBL 128 (2009) 781-802.

Gould, E., "The Alexandrian Gospel”, JBL 19 (1900) 5-11.

Hallo, W. - Lawson, K., The Context of Scripture, Leiden - Boston 2003. 
HaRt, G., The Routledge Dictionary of God and Goddesses, London - New York 2005.

Hoffmeier, J., "Some Thoughts on Genesis 1 \& 2 and Egyptian Cosmology", Journal of the Ancient Near Eastern Society 15 (1983) 39-49.

-, Akhenaten and the Origins of Monotheism, Oxford 2015.

Hunter, A., According to John: A New look at the Fourth Gospel, London 1968.

Johnston, G., "Genesis 1 and Ancient Egyptian Creation Myths", Bibliotheca Sacra 165 (2008) 178-194.

Jones, D., "Christianity and the Roman Imperial Cult," ANRW 2.23.2 (1980) 1023-1054.

KeEner, C., The Gospel of John: A Commentary, Volume One \& Two, Peabody 2003.

Kelber, W., “The Birth of a Beginning: John 1.1-18”, Semeia 52 (1990) 121-144.

KySAR, R., The Fourth Evangelist and His Gospel: An examination of Contemporary scholarship, Minneapolis, 1975.

-, Augsburg Commentary on the New Testament: John, Minneapolis 1986.

LEASE, G., "Jewish Mystery Cults since Goodenough", ANRW 2.20.2 (1987) 858880.

LÉon-Dufour, X., Lectura del evangelio de Juan (Jn 1-4), Salamanca 1984.

LINDARS, B., The Gospel of John, London I972.

Magezi, V. - Manzanga, P., "A study to establish the most plausible background to the Fourth Gospel (John)", HTS Teologiese Studies / Theological Studies 66 (2010).

Magyar, Z., "Imperial Cult and Christianity", Acta Archaeologica Academiae Scientiarum Hung. 60 (2009) 385-395.

Manzanga, P., A Study of the Background of the Concepts "Life" and "Light" in the prologue of the Fourth Gospel (Tesis Magister en Nuevo Testamento presentada en North West University, Potchefstroom Campus), 2007.

Miller, E., Salvation History in the Prologue of John, Leiden - New York - Copenhagen - Köln 1989.

-, "The Johannine Origins of the Johannine Logos", JBL 112 (1993) 445-457.

Morgenstern, J., "The King-God among the Western Semites and the Meaning of Epiphanes", VT 10 (1960) 138-197.

OCKLE, W., "State Archives in Graeco-Roman Egypt from $30 \mathrm{BC}$ to the Reign of Septimius Severus", The Journal of Egyptian Archaeology 70 (1984) 106-122.

PAGELs, E., "Exegesis of Genesis 1 in the Gospels of Thomas and John", JBL 118 (1999) 477-496.

Painter, J., "Rereading Genesis in the Prologue of John", en P. Borgen - D. Aune et als (eds.), Neotestamenta et Philonica: Studies in Honour of Peder Borgen, Leiden - Boston - Köln 2002, 179-201.

-, "The Point of John's Christology - Christology, Conflict and Community in John", en D. Horrell - C. TuckettT (eds.), Christology, Controversy and Community - New Testament Essays in Honour of David R. Catchpole, Leiden - Boston - Köln 2000, 231-252. 
Parrott, D., "Gnosticism and Egyptian Religion”, Novum Testamentum 27 (1989) 73-93.

Penna, R., Ambiente histórico-cultural de los orígenes del cristianismo, Bilbao 1994.

Perkins, P., "Logos Christologies in the Nag Hammadi Codices", Vigiliae Christianae 35 (1981) 379-396.

Perry, A., "Is John an Alexandrian Gospel?", JBL 63 (1944) 99-106.

Price, S., "Between Man and God: Sacrifice in the Roman Imperial Cult", The Journal of Roman Studies 70 (1980) 28-43.

SAYCE, A., "The Egyptian Background of Genesis I", Studies Presented to F. Ll. Griffith, London 1932.

Schnackenburg, R., The Gospel According to John, Vol. 1, London 1968.

-, The Gospel According to St John, Vol. 2, New York 1979.

Shetter, T., "Genesis 1-2 In Light of Ancient Egyptian Creation Myths" (artículo presentado en la Student Academic Conference del Dallas Theological Seminary, 18 de abril de 2005).

Simpson, W., The Literature of Ancient Egypt, New Haven - London 2003.

SNAPE, H., "The Fourth Gospel, Ephesus, and Alexandria", HTR 47 (1954) 1-14.

VAN Winden J., "In the Beginning: Some Observations on the Patristic Interpretation of Genesis 1:1", Vigiliae Christianae 17 (1963) 105-121.

Withrow, G., "The Gospel of John. Creation and Liturgy", disponible en http:// www.holytrinityparish.net/wp-content/uploads/2014/11/The_Gospel_of_ John2.pdf. 